\title{
Al-Madãris
}

VOL. 1, NO. 12020

E-ISSN: 2745-9950

https://journal.staijamitar.ac.id/index.php/almadaris

\section{TEKANAN UDARA DALAM PERSPEKTIF SAINS DAN AL-QUR'AN}

\author{
Nuraini Fatmi \\ Program Studi Pendidikan Fisika Universitas Malikussaleh \\ nurainifatmi@unimal.ac.id
}

\begin{abstract}
The objectives of this study are: 1 . To see the function of air pressure from a scientific perspective. 2. To see the function of air pressure in the perspective of the Qur'an. 3. To see the relationship between the study of the function of air pressure from a scientific perspective and the Koran. This study used qualitative research methods. The type of research used in this research is library research. The instrument in qualitative research is a person or human instrument, namely the researcher himself. As a human instrument in this study, researchers must have broad insight and theory in order to be able to ask, analyze, take pictures and construct the social conditions under study to be clearer and show. The technique of reading data that researchers use in library research is by reading, interviewing and triangulation. Research results: 1. Study of Air Pressure Function in Science Perspective is according to science air pressure is a force that moves air particles carrying air particles in the direction of the earth's force. 2. The study of the function of air pressure in the perspective of the Koran is based on the perspective of the Koran, the air pressure is described into the atmospheric layer which is described in QS: Al-An'am (6) verse 125. 3. The relationship between the study of the pressure function The air in the perspective of science and the Koran is the relationship between science and the Qur'an expressed as an integrated relationship. This integration can be described in two forms, namely natural theology (natural theology) which views scientific findings as a means of reaching God, and natural theology (theology of nature).
\end{abstract}

Keywords: Islamic science, al-Qur'an.

$\overline{\text { Al-Madaris, Volume l (1), } 2020}$ 


\section{A. Pendahuluan}

Udara terbentuk dari campuran gas yang diperlukan oleh semua makhluk seperti manusia, tanaman dan hewan untuk hidup. Ketika bergerak, udara menekan segala sesuatu yang dilaluinya, misalnya daun berdesir dan layangan yang terangkat tinggi. Gerakan udara yang disebabkan oleh tekanan disebut angin. Udara yang tak bergerak juga menekan. Perlu diketahui bahwa bumi dikelilingi oleh lapisan udara setebal $640 \mathrm{~km}$.

Tekanan udara adalah tenaga yang bekerja untuk menggerakkan massa udara dalam setiap satuan luas tertentu. Diukur dengan menggunakan barometer. Satuan tekanan udara adalah milibar (mb). Garis yang menghubungkan tempattempat yang sama tekanan udaranya disebut sebagai isobar. Tekanan udara merupakan tingkat kebasahan udara karena dalam udara air selalu terkandung dalam bentuk uap air. kandungan uap air dalam udara hangat lebih banyak daripada kandungan uap air dalam udara dingin. kalau udara banyak mengandung uap air didinginkan maka suhunya turun dan udara tidak dapat menahan lagi uap air sebanyak itu. uap air berubah menjadi titik-titik air. udara yang mengandung uap air sebanyak yang dapat dikandungnya disebut udara jenuh.

Sains merupakan hasil nyata pemikiran manusia yang membawa sudut pandang tertentu dalam memahami suatu peristiwa atau realitas. Saat ini kemajuan zaman modern bertolak pada perkembangan sains dan teknologi yang kini mengalami perkembangan yang sangat pesat. Perkembangan sains atau ilmu pengetahuan ini disebabkan karena adanya ketidak percayaan ilmuwan terhadap teori-teori tertentu (Agus Purwanto, 2015: 25).

Berdasarkan hasil observasi penulis pada beberapa literature, penulis menemukan bahwa pengetahuan tentang sains dalam perspektif al-Qur'an masih kurang, khususnya pada pokok bahasan tekanan, sedangkan secara sains dalam al-Qur'an juga masih sangat kurang, hal ini mungkin di sebabkan oleh kurang nya literasi di perpustakaan. Berdasarkan hal inilah penulis mencoba melakukan penelitian tenatang tekanan udara dalam perspektif sains dan al-Qur'an.

\section{B. Review Literatur}

Alam memperlihatkan keteraturan yang luar biasa, semua memunculkan suatu kebenaran yang mendasar, suatu kesatuan dari kontrol yang sudah ditetapkan ketentuannya. Hal tersebut mengacu pada suatu pengawasan dan kontrol dari Dzat Yang Agung yakni Sang Pencipta (M. Afif Anshori, 2011: 79). Kita pelajari secara teoritis dengan kebenaran-kebenaran yang telah dijelaskan di dalam al-Qur'an. Namun hal itu bukan berarti kita dapat mengait-ngaitkan ayat al-Qur'an dengan sesuka hati guna meperkuat suatu teori.

Terdapat beberapa ayat dalam al-Qur'an memerintahkan manusia untuk memanfaatkan akal fikiran, penalaran dan sebagainya agar dapat memahami sesuatu. Hal-hal seperti ini yang menyebabkan adanya iklim dalam ilmu pengetahuan dan yang sudah melahirkan berbagai disiplin ilmu. Dalam hal ini Quraish Shihab membagi dua korelasi antara al-Qur'an dan ilmu pengetahuan, yaitu: Pertama, al-Qur'an memerintahkan manusia menggunakan fikirannya untuk mendapatkan ilmu pengetahuan yang seluas-luasnya. Kedua, banyak Al-Madãris, Volume 1 (1), 2020 
ditemukan ayat al-Qur'an yang membahas alam semesta dan fenomena yang terjadi di dalamnya (Umul Aiman, 2011: 52)

Ilmu-ilmu Tuhan menyebar ke seluruh langit dan bumi. Bahkan langit dan bumi itu sendiri adalah realitas pengetahuan Tuhan. Ini adalah pengetahuan tentang Tuhan yang kemudian dipelajari oleh manusia dalam bentuk sains dan teknologi. Ilmu pengetahuan adalah penguasaan teoritis, sementara teknologinya praktis. Manusia tidak pernah menciptakan pengetahuan, tapi hanya merumuskan kenyataan. Salah satu benda yang fungsinya begitu penting sebagai sumber kehidupan di bumi adalah tekanan udara.

Berdasarkan perspektif al-Quran tekanan udara di deskripsikan kedalam lapisan atmosfer, adapun kemungkinan sebagai tempat berlangsungnya kehidupan, lapisan atmosfer bumi bisa dibagi menjadi 3 kategori, yaitu:

\section{Lapisan Bawah}

Lapisan ini berada sampai ketinggian $3 \mathrm{~km}$ di atas permukaan laut. Pada lapisan ini manusia bisa bernafas dan melangsungkan kehidupannya tanpa dihadapkan para resiko-resiko kesehatan. Pasalnya, kondisi di lapisan ini cocok dengan fungsi-fungsi organ tubuh manusia.

\section{Lapisan Tengah}

Lapisan ini berada pada ketinggian 3-16 km diatas permukaan laut. Ciri khas lapisan ini adalah berkurangnya kadar oksigen secara gradual dan turunnya tekanan pada pembuluh darah seiring dengan semakin tingginya seseorang naik ke atas. Manusia bisa hidup pada lapisan terbawah dari lapisan tengah ini, tetapi dengan berbagai kesulitan yang akan dihadapinya. Pasalnya, ia akan menghadapi kekacauan fungsi-fungsi organ tubuh sebagai akibat dari menurunnya tekanan pada pembuluh darah.

\section{Lapisan Atas.}

Lapisan ini berada pada ketinggian $16 \mathrm{~km}$ hingga batas teratas dari atmosfer bumi, yang mencapai $1000 \mathrm{~km}$ lebih. Manusia tidak bisa bertahan hidup pada lapisan ini tanpa menggunakan alat khusus.

Oleh sebab itu, pesawat yang terbang pada ketinggian $12 \mathrm{~km}$ diberi tambahan tekanan sebanyak 8 kali lipat agar tekanan udara dalam pesawat sama dengan yang ada di lapisan bawah. Jika tidak demikian, semua penumpang bisa benar-benar tak sadarkan diri. Apabila perangkat penambah tekanan udara yang ada dalam pesawat tidak bekerja dengan baik selama terbang di udara, pilot harus secepatnya mendaratkan pesawatnya. Jika tidak, maka semua penumpang bisa mati.

Berdasarkan uraian yang telah diuraikan, agar penelitian ini lebih terfokus, maka peneliti memfokuskan area spesifik penelitian yaitu pada: "Kajian Fungsi Tekanan Udara dalam Perspektif Sains dan al-Qur'an". Adapun sub fokus penelitian ini yaitu: 1. Kajian fungsi tekanan udara dalam perspektif sains. 2. Kajian fungsi tekanan udara dalam perspektif al-Qur'an. 3. Hubungan antara kajian fungsi tekanan udara dalam perspektif sains dan al-Qur'an.

$\overline{\text { Al-Madãris, Volume l (1), } 2020}$ 


\section{Metodelogi}

Penelitian ini menggunakan metode kualitatif. Metode penelitian kualitatif sering disebut metode penelitian naturalistik karena penelitiannya dilakukan pada kondisi yang alamiah (natural setting) (Sugiyono, 2016: 30). Jenis dan sifat dari penelitian ini yaitu: Jenis penelitian yang digunakan dalam penelitian ini yaitu jenis penelitian studi pustaka (library research). Studi pustaka (library research) adalah serangkaian kegiatan yang berhubungan dengan metode mengumpulkan data pustaka melalui kegiatan membaca, mencatat dan mengolah data penelitian. Penelitian ini bersifat deskriptif. Oleh karena itu hasil dari penelitian ini akan berisi kutipan-kutipan data untuk memberikan gambaran penyajian hasil penelitian (Mestika Zed, 2017: 73). Instrumen dalam penelitian kualitatif adalah orang atau human instrument yaitu peneliti itu sendiri. Sebagai human instrument dalam penelitian ini, peneliti harus mempunyai wawasan dan bekal teori yang luas agar mampu bertanya, menganalisa, memotret dan mengkonstruksi kondisi sosial yang diteliti menjadi lebih jelas dan bermakna (Sugiyono, 2016: 31-34). Untuk dapat meneliti dan memperoleh data-data yang valid dan terjamin keotentikannya, maka digunakan sumber data primer dan sumber data sekunder. Teknik pengumpulan data yang peneliti gunakan dalam penelitian kepustakaan ini yaitu dengan teknik membaca, wawancara dan triangulasi. Dalam penelitian kualitatif analisis data menggunakan pendekatan analisis induktif, yaitu dimulai dari mengamati fenomenafenomena secara empiris, yang selanjutnya mempolakan atau menafsirkan hasil penelitian tersebut kemudian diinterpretasikan sebagai kesimpulan untuk membangun teori atau hipotesis. Teknik analisis data yang peneliti gunakan dalam penelitian ini yaitu teknik analisis data model Milles dan Huberman, dengan langkah-langkah sebagai berikut: 1) reduksi data; 2) penyajian data/display data; 3) Penarikan kesimpulan/verifikasi.

\section{Hasil Penelitian}

\section{Kajian Fungsi Tekanan Udara dalam Perspektif Sains}

Menurut ilmu sains tekanan udara adalah sebuah tenaga yang menggerakkan massa partikel udara menekan searah gaya gravitasi bumi. Tekanan udara akan berbanding terbalik dengan ketinggian suatu tempat sehingga semakin tinggi tempat dari permukaan laut maka akan semakin rendah tekanan udaranya. Kondisi ini disebabkan karena semakin tinggi suatu tempat maka akan semakin berkurang udara yang menekannya. Tekanan udara di puncak gunung berbeda dengan tekanan udara yang ada di pantai. Hal ini disebabkan dipuncak gunung jumlah partikel udaranya semakin kecil yang mengakibatkan gaya gravitasinya kecil sehingga tekanan pada udaranya pun akan semakin kecil. Tekanan udara dapat diukur dengan menggunakan Barometer, dengan satuan milibar (mb) dan garis yang menghubungkan tempat-tempat yang sama pada tekanan udaranya disebut isobar.

Tekanan udara diukur berdasarkan tekanan gaya pada permukaan dengan luas tertentu, misalnya $1 \mathrm{~cm}^{2}$. Satuan yang digunakan adalah atmosfer (atm), millimeter kolom air raksa ( $\mathrm{mmHg}$ ) atau milibar (mbar). Tekanan udara patokan

$\overline{\text { Al-Madaris, Volume l (1), } 2020}$ 
(sering juga disebut) tekanan udara normal) adalah tekanan kolom udara setinggi lapisan atmosfer bumi pada garis lintang 450 dan suhu $00^{C}$. besarnya tekanan udara tersebut dinyatakan sebagai $1 \mathrm{~atm}$. Tekanan sebesar 1 atm ini setara dengan tekanan yang diberikan oleh kolom air raksa setinggi $760 \mathrm{~mm}$. satuan tekanan selain dengan atm atau mmHg juga dapat dan sering dinyatakan dalam satuan $\mathrm{kg} / \mathrm{m}^{2}$, konversi antara satuan tekanan udara tersebut adalah sebagai berikut 1 $\mathrm{atm}=760 \mathrm{mmHg}=14,7 \mathrm{Psi}=1,013 \mathrm{mbar}$ (Mulyatno, 2014:80).

\section{Kajian fungsi tekanan udara dalam perspektif al-Qur'an}

Berdasarkan perspektif al-Quran tekanan udara di deskripsikan kedalam lapisan atmosfer, adapun kemungkinan sebagai tempat berlangsungnya kehidupan.

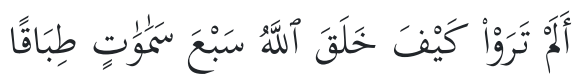

Artinya: "Tidakkah kamu perhatikan bagaimana Allah telah menciptakan tujuh langit bertingkat-tingkat." (an-Nuh-15)

Seperti telah dijabarkan di atas, bumi dilindungi oleh tujuh lapis atmosfer. Penelitian mengenai atmosfer baru dimulai abad ke-17, jauh setelah al-Qur'an diturunkan.

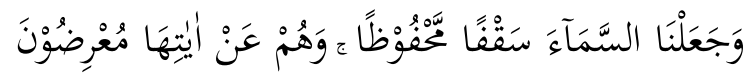

Artinya: "Dan Kami menjadikan langit itu sebagai atap yang terpelihara, sedang mereka berpaling dari segala tanda-tanda (kekuasaan Allah) yang terdapat padanya." (alAnbiya'-32)

Kata "atap yang terpelihara" adalah terjemahan Bahasa Indonesia-nya. Sementara dalam Bahasa Inggris, ayat tersebut diterjemahkan menjadi "protected ceiling" (atap yang terlindungi). Fungsi utama dari tujuh lapisan atmosfer adalah untuk melindungi permukaan bumi dari benda-benda asing seperti meteor, serta sinar ultraviolet berlebih.

Lapisan di atas melindungi lapisan di bawahnya, menjadikan lapisan di bawahanya layaknya atap yang terlindungi.

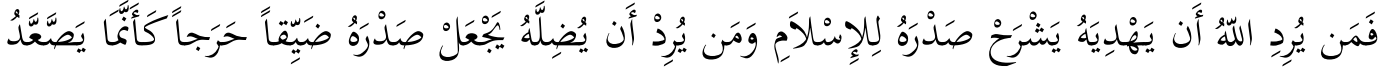

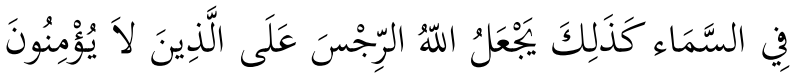

Artinya: "Barangsiapa yang Allah menghendaki akan memberikan kepadanya petunjuk, niscaya Dia melapangkan dadanya untuk (memeluk) Islam. Dan barangsiapa yang dikehendaki Allah kesesatannya, niscaya Allah menjadikan dadanya sesak lagi sempit, seolah-olah ia sedang mendaki langit. Begitulah Allah menimpakan siksa kepada orang-orang yang tidak beriman." (al-An'am-125)

Semakin kita bergerak ke atas, maka semakin susah kita untuk bernafas. Bukan karena oksigen semakin tipis, namun karena tekanan udara semakin berkurang. Di ketinggian, seperti di gunung misalnya, tekanan udaranya 30\% lebih rendah dari permukaan laut. Hal ini membuat oksigen susah masuk ke

$\overline{\text { Al-Madãris, Volume l (1), } 2020}$ 
dalam sistem pernapasan kita karena pergerakan molekulnya lebih lambat (Abdul. M, 2002: 97).

\section{Hubungan antara kajian fungsi tekanan udara dalam perspektif sains dan al-Qur'an}

Kata sains dan teknologi ibarat dua sisi mata uang yang sulit dipisahkan satu sama lain. Sains, menurut Baiquni, adalah himpunan pengetahuan manusia tentang alam yang diperoleh sebagai konsensus para pakar, melalui penyimpulan secara rasional mengenai hasil-hasil analisis yang kritis terhadap data pengukuran yang diperoleh dari observasi pada gejala-gejala alam. Sedangkan teknologi adalah himpunan pengetahuan manusia tentang proses-proses pemanfaatan alam yang diperoleh dari penerapan sains, dalam kerangka kegiatan yang produktif ekonomis (Baiquni, 1995: 67).

Al-Qur'an, sebagai kalam Allah, diturunkan bukan untuk tujuan-tujuan yang bersifat praktis. Oleh sebab itu, secara obyektif, al-Qur'an bukanlah ensiklopedi sains dan teknologi apalagi al-Qur'an tidak menyatakan hal itu secara gamblang. Pandangan al-Qur'an tentang sains dan teknologi dapat ditelusuri dari pandangan al-Qur'an tentang ilmu. Al-Qur'an telah meletakkan posisi ilmu pada tingkatan yang hampir sama dengan iman seperti tercermin dalam surat al-Mujadalah ayat 11 :

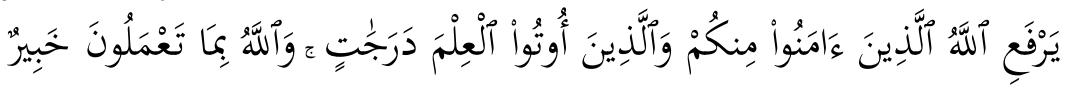

Artinya: "..niscaya Allah akan meninggikan orang-orang yang beriman di antara kamu dan orang-orang yang diberi ilmu pengetahuan beberapa derajat."(al-Mujadalah-11)

Ayat-ayat al-Qur'an yang memerintahkan manusia mencari ilmu atau menjadi ilmuwan begitu banyak. Al-Qur'an menggunakan berbagai istilah yang berkaitan dengan hal ini. Misalnya, mengajak melihat, memperhatikan, dan mengamati kejadian-kejadian (Fathir: 27; al-Hajj: 5; Luqman: 20; al- Ghasyiyah: 17-20; Yunus: 101; al-Anbiya': 30), membaca (al-'Alaq: 1-5) supaya mengetahui suatu kejadian (al-An'am: 97; Yunus: 5), supaya mendapat jalan (al-Nahl: 15), menjadi yang berpikir atau yang menalar berbagai fenomena (alNahl: 1l; Yunus: 101; al-Ra'd: 4; al-Baqarah: 164; al-Rum: 24; al-Jatsiyah.

Adapun mengenai tekanan udara di dalam al-Quran Seperti yang telah dijabarkan di atas, bumi dilindungi oleh tujuh lapis atmosfer. Penelitian mengenai atmosfer baru dimulai abad ke-17, jauh setelah al-Qur'an diturunkan.

Hubungan antara sains dan al-Qur'an itu dinyatakan sebagai hubungan terintegrasi. Integrasi ini bisa digambarkan dalam dua bentuk yakni teologi natural (natural theology) yang memandang bahwa temuan-temuan ilmiah itu merupakan sarana mencapai Tuhan, dan teologi alam (theology of nature) yang menganggap bahwa pertemuan dengan Tuhan harus senantiasa di-up grade sesuai dengan perkembangan ilmu pengetahuan (Barbour, 2005: 99).

$\overline{\text { Al-Madãris, Volume l (1), } 2020}$ 


\section{E. Pembahasan}

1. Hakikat ilmiahnya:

Manakala terangkat manusia ke langit, tekanan udara menjadi rendah dan kuantiti oksigen akan sedikit sehingga dada menjadi sempit dan susah bernafas. Sebab jika orang ke puncak Gunung Everest akan membawa tangki oksigen sebab lapisan udara menipis dan terjadi sesak nafas bila sampai ke puncak serta kandungan oksigen kurang tekanan.

\section{Tafsir ilmiah:}

Dari ayat muhkamat di atas mengisyaratkan secara jelas dua kenyataan yang telah ditemukan oleh ilmu pengetahuan manusia: Pertama, perubahan yang luar biasa pada tekanan udara ketika naik dengan cepat ke langit menyebabkan dada manusia menjadi sesak dan sempit. Kedua, ketika manusia terangkat ke langit, tekanan udara menjadi rendah dan jumlah oksigen akan berkurang sehingga dada menjadi sesak dan susah bernafas.

Pembahasan ilmiah yang di jelaskan secara sains jauh-jauh hari sebelum ilmu pengetahuan berkembang, hal ini sudah di buktikan oleh al-Qu'an sebagaimana tersebut dalam al-An'am-125 "Barangsiapa yang Allah menghendaki akan memberikan kepadanya petunjuk, niscaya Dia melapangkan dadanya untuk (memeluk) Islam. Dan barangsiapa yang dikehendaki Allah kesesatannya, niscaya Allah menjadikan dadanya sesak lagi sempit, seolah-olah ia sedang mendaki langit. Begitulah Allah menimpakan siksa kepada orang-orang yang tidak beriman."

Sesuai bunyi ayat di atas maka ilmu pengetahuan tentang tekanan udara sudah di jelaskan di dalam al-Qur'an, Dalam Ensiklopedi Internasional juga menjelaskan bahwasanya kumpalan udara yang besar tidaklah didistribusikan secara merata dan lurus, sekitar $50 \%$ kumpalan udara terhimpun di permukaan bumi dan naik 20 ribu kaki ke permukaan laut, $90 \%$ dari permukaan bumi dan naik 50 ribu kaki dari permukaan bumi. Akibatnya kepadatan udara berkurang dengan cepat ketika kita naik atau terangkat secara vertikel sehingga jika kita terangkat pada level yang tinggi kepadatan udara akan sampai ke level yang sangat rendah. Juga dijelaskan semua makhluk membutuhkan oksigen kecuali makhluk-makhluk yang bersel satu. Sebagai ilustrasi, kebiasaan manusia menghiruf oksigen agar tetap hidup dan menjaga dari tekanan udara pada level tertentu. Keberadaan manusia kurang dari 10 ribu kaki di atas permukaan laut tidak terlalu serius menyebabkan manusia kesulitan bernafas, dan jika berada di atas 10 ribu atau sampai 25 ribu kaki kemungkinan bisa bernafas tetapi sistem pernafasan manusia (respiratory system) akan sulit beradaptasi karena terlalu sempit. Dan jika berada di tingkat paling tinggi manusia sama sekali tidak akan bisa bernafas bahkan bisa menyebabkan kematian karena sedikit oksigen yang diperoleh. Penjelasan ini sangat senada dengan QS: al-An'am (6) ayat 125.

\section{F. Kesimpulan}

Menurut ilmu sains tekanan udara adalah sebuah tenaga yang menggerakkan massa partikel udara menekan searah gaya gravitasi bumi. Dalam perspektif al-Quran tekanan udara di deskripsikan ke dalam lapisan atmosfer, adapun kemungkinan sebagai tempat berlangsungnya kehidupan, hal ini seperti

$\overline{\text { Al-Madãris, Volume 1 (1), } 2020}$ 
dijelaskan dalam Q.S. al-An'am (6) ayat 125. Semakin kita bergerak ke atas, maka semakin susah kita untuk bernafas. Bukan karena oksigen semakin tipis, namun karena tekanan udara semakin berkurang. Di ketinggian, seperti di gunung misalnya, tekanan udaranya 30\% lebih rendah dari permukaan laut. Hal ini membuat oksigen susah masuk ke dalam sistem pernapasan kita karena pergerakan molekulnya lebih lambat. Hubungan antara sains dan al-Qur'an itu dinyatakan sebagai hubungan terintegrasi. Integrasi ini bisa digambarkan dalam dua bentuk yakni teologi natural (natural theology) memandang bahwa temuantemuan ilmiah itu merupakan sarana mencapai Tuhan, dan teologi alam (theology of nature) yang menganggap bahwa pertemuan dengan Tuhan harus senantiasa diup grade sesuai dengan perkembangan ilmu pengetahuan.

\section{BIBLIOGRAFI}

Abu Ja'far Muhammad ibn Jarir at-Thabari. (2007). Tafsir at-Thabari. Terj. Ahsan Askan. Vol. 1. Jakarta: Pustaka Azzam.

Ahmad As Shouwy dkk. (1997). Mukjizat al-Qur'an dan As-sunnah tentang IPTEK. Jakarta: Gema Insani Press.

Al-Ghazali, Syekh Imam. (2002). Keajaiban Dua Makhluk Allah. Surabaya: Pustaka Media.

An-Najjar. Prof. dr. Zaghlul. (2011). Sains Dalam Hadis. AMZAH: Jakarta.

Baiquni, Achmad. (1995). Al-Qur'an, Ilmu Pengetahuan dan Teknologi. Yogyakarta: Dana Bhakti Wakaf.

Barbour, Ian G. (2005). Menemukan Tuhan dalam Sains Kontemporer dan Agama, Bandung: Mizan.

Bucaille, Maurice. (1979). Bibel, Al-Qur'an dan Sains Modern. Jakarta: Bulan Bintang

Giancoli, (2001), Fisika Dasar, Jilid 2 Edisi Kelima, Penerbit Erlangga, Jakarta.

Halim, Abdul. M. (2002). Memahami al-Quran Pendekatan Gaya \& Tema. Bandung: Penerbit Marja'

Imani, Allamah Kamal. (2006). Tafsir Nurul Qur'an. Jakarta: Nurul Huda

Kementrian Agama RI. (2010). Penciptaan Bumi Dalam" Perspektif al-Quran \& Sains". Lajnah Pentashilan Mushaf al-Quran

Kementrian Agama RI. (2010). Penciptaan Manusia dalam Perspektif al-Quran \& Sains”. Lajnah Pentashihan Mushaf al-Quran

Mestika Zed. (2017). Metode Penelitian Kepustakaan. Jakarta: Yayasan Pustaka Obor Indonesia

Mulyatno. (2014). Materi Pokok Fisika Umum. Tangerang Selatan: Universitas Terbuka

Nasi, Ar-Rifai. M. (2000). Kemudahan dari Allah Ringlasan Tafsir Ibnu Katsir. Jilid ke-3. Jakarta: Gema Insani Press.

Purwanto, Agus. (2008). Ayat-ayat Semesta Sisi al-Qur'an Yang Terlupakan. Bandung: Mizan

Shihab, Quraish. M. (2002). Tafsir Al-Misbah Pesan, Kesan \& Keserasian al-Quran. vol.1l Jakarta: Lentera Hati.

$\overline{\text { Al-Madãris, Volume 1 (1), } 2020}$ 